\title{
Insights into the anticancer properties of the first antimicrobial peptide from Archaea
}

Article in Biochimica et Biophysica Acta (BBA) - General Subjects · June 2017

DOI: 10.1016/j.bbagen.2017.06.009

CITATIONS

0

15 authors, including:

\section{Annarita Del Gatto}

University of Naples Federico II

41 PUBLICATIONS 345 CITATIONS

SEE PROFILE

\section{Emilia Maria Pedone}

Italian National Research Council

94 PUBLICATIONS 1,202 CITATIONS

SEE PROFILE
READS

51

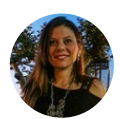

Angela Arciello

University of Naples Federico II

30 PUBLICATIONS 661 CITATIONS

SEE PROFILE

\section{Patrizia Contursi}

University of Naples Federico II

33 PUBLICATIONS 449 CITATIONS

SEE PROFILE

Some of the authors of this publication are also working on these related projects:

TheViriozymes (Thermostable Virion-linked Enzymes): robust virus particles as tailorable scaffolds for the immobilization of enzymes View project 


\title{
Insights into the anticancer properties of the first antimicrobial peptide from Archaea
}

\author{
Rosa Gaglione $^{\mathrm{a}, 1}$, Luciano Pirone ${ }^{\mathrm{b}, 1}$, Biancamaria Farina ${ }^{\mathrm{b}, \mathrm{c}, 1}$, Salvatore Fusco ${ }^{\mathrm{d}, \mathrm{j}, 1}$, \\ Giovanni Smaldone $^{\mathrm{e}}$, Martina Aulitto ${ }^{\mathrm{d}}$, Eliana Dell'Olmo ${ }^{\mathrm{a}}$, Emanuela Roscetto ${ }^{\mathrm{f}}$, \\ Annarita Del Gatto $^{\text {b,g }}$, Roberto Fattorusso ${ }^{\text {g,h }}$, Eugenio Notomista ${ }^{\mathrm{d}}$, Laura Zaccaro ${ }^{\mathrm{b}, \mathrm{g}}$, \\ Angela Arciello $^{\mathrm{a}, \mathrm{i}, *}$, Emilia Pedone ${ }^{\mathrm{b}, g_{, * *}, 2}$, Patrizia Contursi ${ }^{\mathrm{d}, * * *, 2}$ \\ a Department of Chemical Sciences, University of Naples Federico II, 80126 Naples, Italy \\ ${ }^{\mathrm{b}}$ Institute of Biostructures and Bioimaging, Italian Research National Council, Naples, Italy \\ ${ }^{c}$ Advanced Accelerator Applications, 81100 Caserta, Italy \\ d Department of Biology, University of Naples Federico II, Complesso Universitario Monte S. Angelo, Via Cinthia, 80126 Naples, Italy. \\ e IRCCS SDN, Via E. Gianturco 113, 80143 Naples, Italy \\ ${ }^{\mathrm{f}}$ Department of Molecular Medicine and Medical Biotechnology, Federico II University Medical School, Italy \\ ${ }^{g}$ Research Centre on Bioactive Peptides (CIRPeB), University of Naples "Federico II", Via Mezzocannone 16, 80134 Naples, Italy \\ h Department of Environmental, Biological and Pharmaceutical Sciences and Technologies, University of Campania-Luigi Vanvitelli, 81100 Caserta, Italy \\ ${ }^{\mathrm{i}}$ National Institute of Biostructures and Biosystems (INBB), Italy \\ ${ }^{\mathbf{j}}$ Division of Industrial Biotechnology, Department of Biology and Biological Engineering, Chalmers University of Technology, Göteborg, Sweden
}

\section{A R T I C L E I N F O}

\section{Keywords:}

Antimicrobial peptide

Anticancer peptide

Sulfolobus

Archaea

Peptide-membrane interactions

\begin{abstract}
A B S T R A C T
Background: The peptide VLL-28, identified in the sequence of an archaeal protein, the transcription factor Stf76 from Sulfolobus islandicus, was previously identified and characterized as an antimicrobial peptide, possessing a broad-spectrum antibacterial activity.

Methods: Through a combined approach of NMR and Circular Dichroism spectroscopy, Dynamic Light Scattering, confocal microscopy and cell viability assays, the interaction of VLL-28 with the membranes of both parental and malignant cell lines has been characterized and peptide mechanism of action has been studied. Results: It is here demonstrated that VLL-28 selectively exerts cytotoxic activity against murine and human tumor cells. By means of structural methodologies, VLL-28 interaction with the membranes has been proven and the binding residues have been identified. Confocal microscopy data show that VLL-28 is internalized only into tumor cells. Finally, it is shown that cell death is mainly caused by a time-dependent activation of apoptotic pathways.

Conclusions: VLL-28, deriving from the archaeal kingdom, is here found to be endowed with selective cytotoxic activity towards both murine and human cancer cells and consequently can be classified as an ACP.

General significance: VLL-28 represents the first ACP identified in an archaeal microorganism, exerting a transkingdom activity.
\end{abstract}

\section{Introduction}

Antimicrobial peptides (AMPs) are short peptides endowed with direct and broad-spectrum antimicrobial activity and represent essential components of the innate immune system of higher eukaryotes, being the first line of defense against microbial invasions $[1,2]$. In addition to a direct antimicrobial action, AMPs show a wide panel of biological activities including anti-inflammatory, anti-viral, chemoattractive and pro-angiogenic activity [1,3-6]. AMPs are very heterogeneous in length, amino-acid composition, secondary structure and mechanism of action; however, the majority of them shows a peculiar abundance of cationic and hydrophobic residues. These AMPs, also

\footnotetext{
* Correspondence to: A. Arciello, Department of Chemical Sciences, University of Naples Federico II, 80126 Naples, Italy.

** Correspondence to: E. Pedone, Institute of Biostructures and Bioimaging, Italian Research National Council, Naples, Italy.

*** Corresponding author.

E-mail addresses: anarciel@unina.it (A. Arciello), empedone@unina.it (E. Pedone), contursi@unina.it (P. Contursi).

${ }^{1}$ These authors equally contributed.

${ }^{2}$ These authors equally contributed to the study and are therefore both last names on this manuscript.
} 
called Host Defence Peptides (HDPs) [7], kill bacterial cells through a specific mechanism i.e. targeting bacterial membranes $[2,6,8]$ : the net positive charge drives the adsorption of the peptide onto the surface of bacterial membranes which are richer in anionic lipids than eukaryotic membranes, hence the hydrophobic residues mediate the insertion of the peptide into the membrane. The accumulation of peptide molecules in the membrane causes the alteration of its structure/permeability, accompanied by a severe impairment of the membrane functions that eventually lead to the death of bacterial cells, often by cell lysis $[2,6,8]$. Since eukaryotic plasma membranes show an asymmetric distribution of negatively charged phospholipids, generally present only in the inner leaflet of the membrane, HDPs are not able to effectively adsorb to eukaryotic cells. The presence of cholesterol further prevents the insertion into and the perturbation of the eukaryotic membranes. Nonetheless, it is worth mentioning that at high concentration several HDPs become toxic also for eukaryotic cells.

Intriguingly, several AMPs endowed with anti-cancer activity [9] are defined as "anti-cancer peptides" (ACPs), because they show a much stronger toxicity for cancer cells than that towards normal cells. This differential toxicity has been attributed to the fact that transformation of eukaryotic cells is often associated to alterations of the membrane composition [10], such as: i) loss of the asymmetric distribution of phospholipids with exposure of phosphatidylserine on the outer leaflet, ii) increased production of anionic lipids (e.g. sulfated lipids), sialic acid containing glycolipids and glycoproteins, and sometimes iii) decreased production of cholesterol. Altogether these events lead to an augmented negative charge at the external surface of tumor cells that, in turn, would favor the binding of ACPs. However, differently from bacterial killing mechanisms, the death of tumor cells is not necessarily due to accumulation of the peptide into the membrane followed by their lysis. Indeed, in several cases it has been demonstrated that ACPs are internalized and the cell death occurs upon the interaction with one or more intracellular targets, such as mitochondria, DNA, cytoplasmic and nuclear proteins (e.g. HSP70 [11] and DNA polymerase $\beta$ [12], respectively). Moreover, it is worth noting that these ACPs usually induce apoptosis rather than necrosis [9].

Due to the severe side effects of conventional chemotherapeutic agents and the ability of some tumor cells to develop the multidrug resistant phenotype, ACPs have attracted considerable attention. Indeed, these peptides could help to develop a new generation of anticancer drugs with a mechanism of action well distinguished from those of conventional chemotherapeutic agents.

As not all the HDPs are ACPs and the killing mechanism seems to differ for each ACP and tumor cell line, the rationale development of new antitumor agents based on CAMPs/ACPs requires further investigations. In particular, the identification and characterization of new ACPs could help to better define the requirements for a strong and selective antitumor activity.

Recently, we have developed an in silico tool allowing to identify HDP-like peptides hidden into the sequences of proteins not necessarily involved in host defense [13]. Using this tool we have already identified three new human HDPs [14-16]. Furthermore, we have demonstrated that DNA binding proteins can be a convenient source of new HDP-like peptides by identifying the first HDP from an archaeal protein, the transcription factor Stf76 encoded by the hybrid plasmid-virus pSSVx from Sulfolobus islandicus [17]. This archaeal HDP, named VLL-28 from its sequence [16], has a broad-spectrum antibacterial activity and exhibits selective leakage and fusogenic capability on vesicles with a lipid composition similar to that of bacterial membranes. Moreover, we have shown that VLL-28 retains the ability of the parental protein to bind nucleic acids (both single and double strand DNA). Using a fluorescent derivative, we have demonstrated that VLL-28 localizes not only on the cell membrane but also in the cytoplasm of Escherichia coli, thus suggesting that it could target both membranes and intracellular components of bacterial cells.

Here we report for the first time the characterization of the antitumor activity of VLL-28. By means of a multidisciplinary approach including biochemical, cellular biology and spectroscopic techniques, the action mechanism of VLL-28 has been elucidated. Intriguingly, it has been proved to be an effective ACP able to selectively kill tumor cells by inducing apoptosis.

\section{Materials and methods}

\subsection{Peptide synthesis reagents}

Polypropylene reaction vessels and sintered polyethylene frits were supplied by Alltech Italia (Milan, Italy). NovaSyn TGR resin, 2-(1Hbenzotriazole-1-yl)-1,1,3,3-tetramethyluronium hexafluorophosphate (HBTU), cyano-hydroxyimino-acetic acid ethyl ester (Oxyma) and all amino acids were purchased from Novabiochem-Merck (Nottingham, U.K.). $N, N^{\prime}$-diisopropylethylamine (DIPEA), piperidine, Kaiser test, trifluoroacetic acid (TFA), scavengers, fluorescein isothiocyanate (FITC) and $N$-methylmorpholine (NMM) were purchased from Sigma-Aldrich (Milan, Italy). $N, N$-Dimethylformamide (DMF) was purchased from CARLO ERBA Reagents (Milan, Italy). Acetonitrile (ACN), dichloromethane (DCM) and diethyl ether were purchased from VWR International (Milan, Italy). All aqueous solutions were prepared by using water obtained from a Milli-Q gradient A-10 system (Millipore, 18.2 M $\Omega \cdot \mathrm{cm}$, organic carbon content $\geq 4 \mu \mathrm{g} / \mathrm{L}$ ).

\subsection{Peptide synthesis}

VLL-28 and FITC-VLL-28 (VLL-28 derivative with an additional glycine residue at the C-terminus as spacer and a lysin residue for FITC labeling) peptides were manually synthesized using the fluorenylmethyloxycarbonyl (Fmoc) solid-phase strategy $(0.2 \mathrm{mmol})$. The syntheses were performed on NovaSyn TGR resin (loading $0.24 \mathrm{mmol} /$ $\mathrm{g}$ ), using all standard amino acids. The Fmoc protecting group was removed by treatment with $30 \%$ piperidine in DMF $(3 \times 10 \mathrm{~min})$. The amino acids in 10-fold excess were pre-activated with HBTU (9.8 equiv)/Oxyma (9.8 equiv)/DIPEA (10 equiv) in DMF for 5 min and then added to the resin suspended in DMF. The reaction was performed for $1 \mathrm{~h}$ and the coupling efficiency was assessed by the Kaiser test. In the case of FITC-VLL-28 peptide, once synthesis was completed, the ivDde protecting group of Lys(ivDde) residue was selectively removed by treatment of the peptidyl resin with a solution of $2 \%$ hydrazine in DMF $(20 \times 3 \mathrm{~min})$. FITC labeling was then performed with 2 equiv of fluorescein isothiocyanate and 4 equiv of NMM in DMF for $5 \mathrm{~h}$.

The peptides were finally cleaved off the resins by treatment with a mixture of trifluoroacetic acid (TFA)/water/triisopropylsilane $(95: 2.5: 2.5 \mathrm{v} / \mathrm{v} / \mathrm{v})$ for $3 \mathrm{~h}$ at room temperature. The resins were filtered, the crude peptides were precipitated with diethyl ether, dissolved in $\mathrm{H}_{2} \mathrm{O}$ /ACN solution, and lyophilized. The products were purified by preparative RP-HPLC on a Shimadzu system equipped with a UV-visible detector SPD10A using a Phenomenex Jupiter Proteo column $(21.2 \times 250 \mathrm{~mm} ; 4 \mu \mathrm{m} ; 90 \AA)$ and a linear gradient of $\mathrm{H}_{2} \mathrm{O}$ ( $0.1 \%$ TFA)/ACN (0.1\% TFA) from $10 \%-55 \%$ of ACN (0.1\%TFA) in $15 \mathrm{~min}$ at a flow rate of $20 \mathrm{~mL} / \mathrm{min}$. The collected fractions containing the peptides were lyophilized giving a final yield of about $35 \%$ of each pure product. The identity and purity of the compounds were assessed by the AGILENT Q-TOF LC/MS instrument equipped with a diode array detector combined with a dual ESI source on a Agilent C18 column $(2.1 \times 50 \mathrm{~mm} ; 1.8 \mu \mathrm{m} ; 300 \AA)$ at a flow rate of $200 \mu \mathrm{L} / \mathrm{min}$ and a linear gradient of $\mathrm{H}_{2} \mathrm{O}(0.01 \%$ TFA)/ACN $(0.01 \%$ TFA) from $5 \%-70 \%$ of ACN $(0.01 \% \mathrm{TFA})$ in $15 \mathrm{~min}$.

\subsection{Cell culture}

Malignant SVT2 murine fibroblasts (BALBc 3T3 cells transformed by SV40 virus), parental BALBc 3T3 murine cells, and HEK-293 human embryonic kidney cells were cultured in Dulbecco's Modified Eagle's 
Medium (Sigma-Aldrich), supplemented with 10\% fetal bovine serum (HyClone), $2 \mathrm{mM}$ L-glutamine and antibiotics, in a $5 \% \mathrm{CO}_{2}$ humidified atmosphere at $37^{\circ} \mathrm{C}$. HRCE (Human Renal Cortical Epithelial) cells (Innoprot) were cultured in basal medium, supplemented with $2 \%$ fetal bovine serum, epithelial cell growth supplement and antibiotics, all from Innoprot, in a $5 \% \mathrm{CO}_{2}$ humidified atmosphere at $37^{\circ} \mathrm{C}$ [18].

\subsection{Cytotoxicity assays}

Cells were seeded in 96 -well plates $(100 \mu \mathrm{L}$ per well) at a density of $5 \times 10^{3}$ per well (SVT2, HEK-293, and HRCE cells) or $2.5 \times 10^{3}$ per well (BALBc 3T3 cells). VLL-28 peptide was added to the cells $24 \mathrm{~h}$ after seeding for time- and dose-dependent cytotoxic assays. At the end of incubation, cell viability was assessed by the MTT assay, as previously described [19]. In brief, MTT reagent, dissolved in DMEM in the absence of phenol red (Sigma-Aldrich), was added to the cells (100 $\mu \mathrm{L}$ per well) to a final concentration of $0.5 \mathrm{mg} / \mathrm{mL}$. After a 4-h incubation at $37^{\circ} \mathrm{C}$, the culture medium was removed and the resulting formazan salts were dissolved by adding isopropanol containing $0.1 \mathrm{~N} \mathrm{HCl}$ $(100 \mu \mathrm{L}$ per well). Absorbance values of blue formazan were determined at $570 \mathrm{~nm}$ using an automatic plate reader (MicrobetaWallac 1420, Perkin Elmer). Cell survival was expressed as percentage of viable cells in the presence of the peptide, with respect to control cells grown in the absence of the peptide. In all of the experiments described in this paper, controls were performed by supplementing the cell cultures with identical volumes of peptide buffer for the same time span. Obtained data represent the mean ( \pm standard deviation) of at least 4 independent experiments, each one carried out with triplicate determinations. Statistical analysis was performed using a Student's $t$-Test, and significant differences were indicated as $*(P<0.05)$, $* *(P<0.01)$ or $* * *(P<0.001)$.

\subsection{Analysis of cell death}

Cells were plated in 6-well plates ( $1 \mathrm{~mL}$ per well) at a density of $1 \times 10^{6}$ cells per well in complete medium for $24 \mathrm{~h}$ and then exposed to $20 \mu \mathrm{M}$ VLL-28 for 6,12 or $24 \mathrm{~h}$ to prepare cell lysates. Both untreated and treated cells were scraped off in PBS, centrifuged at $1000 \times g$ for $10 \mathrm{~min}$ and resuspended in lysis buffer (1\% NP-40 in PBS, pH 7.4) containing protease inhibitors. After $30 \mathrm{~min}$ of incubation on ice, lysates were centrifuged at $14,000 \times g$ for $30 \mathrm{~min}$ at $4{ }^{\circ} \mathrm{C}$. Upon determination of total protein concentration in the supernatant by the Bradford assay, samples were analyzed by SDS-PAGE followed by Western blotting using specific antibodies directed towards procaspase3 (Cell Signaling Technology) or p62 (Novus Biologicals) proteins. For normalization to internal standard signals, antibodies against $\beta$-actin (Sigma-Aldrich) were used. In parallel experiments, cells were treated with puromycin $(10 \mu \mathrm{g} / \mathrm{mL})$ for $12 \mathrm{~h}$ or with rapamycin $(20 \mu \mathrm{M})$ for $24 \mathrm{~h}$, which were used as positive controls for apoptosis and autophagy induction, respectively.

For morphological analyses, cells were seeded on glass coverslips in 24-well plates and grown to semi-confluency. Cells were then incubated for $72 \mathrm{~h}$ with $20 \mu \mathrm{M}$ VLL-28 peptide in complete medium, after which cells were washed with PBS, fixed for $10 \mathrm{~min}$ at room temperature (RT) with 4\% paraformaldehyde in PBS and mounted in 50\% glycerol in PBS. Samples were then examined using a confocal laser-scanner microscope Zeiss LSM 700. All images were taken under identical conditions.

\subsection{Fluorescence studies}

Fluorescence analyses were performed as previously described [20]. Briefly, cells were seeded on glass coverslips in 24-well plates, grown to semi-confluency, and then incubated for $12 \mathrm{~h}$ with $20 \mu \mathrm{M}$ FITC-labeled VLL-28. Following incubation, cells were washed with PBS and then fixed for 10 min at RT with 4\% paraformaldehyde in PBS. Cell membranes were labeled by incubating the cells with Wheat Germ
Agglutinin (WGA, $5 \mu \mathrm{g} / \mathrm{mL}$ ) Alexa Fluor ${ }^{\circledR} 594$ Conjugate (ThermoFisher Scientific) for $10 \mathrm{~min}$ at RT. Cells were then washed twice in PBS following the manufacturer's instructions. Confocal microscopy analyses were performed with a confocal laser-scanner microscope Zeiss LSM 700 .

\subsection{Circular dichroism analyses}

Far-UV CD spectra were recorded on a Jasco J-810 spectropolarimeter (JASCO Corp) equipped with a PTC-423S/15 Peltier temperature controller in the wavelength interval of $198-260 \mathrm{~nm}$. Experiments were performed using a $20 \mu \mathrm{M}$ VLL-28 solution (in PBS $\mathrm{pH} 7.4$ ) in a $0.1 \mathrm{~cm}$ path-length quartz cuvette as already reported in Notomista et al. [16].

$\mathrm{CD}$ spectra in the presence of intact cells were registered using $8 \times 10^{5}$ BALBc 3 T3 cells or SVT2 cells at different incubation times $(0$, $10,30,60 \mathrm{~min}$ and $24 \mathrm{~h}$ ) in PBS buffer at $20^{\circ} \mathrm{C}$. The baseline was corrected by subtracting the spectrum of the cells alone at the same time of incubation [21-23].

\subsection{Membrane preparation}

Membranes used in NMR experiments were isolated from BALBc 3T3 or SVT2 cells and obtained as reported in Farina et al. [24]. In details, cells were detached from the flask with trypsin and washed twice with PBS. Then the cells were transferred into homogenization buffer containing PBS and homogenized by means of a pellet pestle (Sigma). Particulate matter was removed by centrifuging at $3500 \mathrm{rpm}$ for $15 \mathrm{~min}$. The supernatant was then centrifuged at $28000 \mathrm{rpm}$ for $1 \mathrm{~h}$ at $4{ }^{\circ} \mathrm{C}$. The pellet was washed and centrifuged at $28000 \mathrm{rpm}$ for $30 \mathrm{~min}$ at $4{ }^{\circ} \mathrm{C} .180 \mu \mathrm{L}$ of PBS plus $20 \mu \mathrm{L} \mathrm{D}_{2} \mathrm{O}$ were added to the pellet, and the membrane was re-suspended by 20 passages through a 25 gauge needle.

\subsection{NMR spectroscopy}

All NMR experiments were carried out at $298 \mathrm{~K}$ using an Inova $600 \mathrm{MHz}$ spectrometer (Varian Inc., Palo Alto, CA, USA), equipped with a cryogenic probe optimized for ${ }^{1} \mathrm{H}$ detection.

NMR samples were prepared as follows. For chemical shift assignment and conformational analysis, $1 \mathrm{mg}$ of VLL-28 was dissolved either in $500 \mu \mathrm{L}$ sodium phosphate $20 \mathrm{mM} \mathrm{pH} 7.0$ with $10 \% \mathrm{v} / \mathrm{v} \mathrm{D}_{2} \mathrm{O}$ or in $500 \mu \mathrm{L}$ of the same buffer containing $25 \%$ (v/v) TFE (2,2,2-trifluoroethanol-D3 99.5\% isotopic purity, Sigma-Aldrich). One-dimensional (1D) ${ }^{1} \mathrm{H}$ spectra were acquired with a spectral width of $7191.66 \mathrm{~Hz}$, relaxation delay $1.03 \mathrm{~s}$, 7k data points for acquisition and 16k for transformation. Bi-dimensional $(2 \mathrm{D})\left[{ }^{1} \mathrm{H},{ }^{1} \mathrm{H}\right]$ total correlation spectroscopy (TOCSY) [25], double quantum filtered correlated spectroscopy (COSY) [26] and nuclear Overhauser effect spectroscopy (NOESY) [27] were acquired with 32 or 64 scans per $t 1$ increment with a spectral width of $7191.66 \mathrm{~Hz}$ along both $\mathrm{t} 1$ and $\mathrm{t} 2,2048 \times 256$ data points in $\mathrm{t} 2$ and $\mathrm{t} 1$, respectively, and recycle delay $1.0 \mathrm{~s}$. Water suppression was achieved by means of Double Pulsed Field Gradient Spin Echo (DPFGSE) sequence $[28,29]$. TOCSY experiments were recorded using a DIPSI-2 mixing scheme of $70 \mathrm{~ms}$ with $7.7 \mathrm{kHz}$ spin-lock field strength. NOESY spectra were carried out with a mixing time of $250 \mathrm{~ms}$. Data were typically apodized with a square cosine window function and zero filled to a matrix of size $4096 \times 1024$ before Fourier transformation and baseline correction.

According to the procedure recently reported [24] for interaction studies of VLL-28 with intact cells and isolated membranes of BALBc 3 T3 and SVT2 cell lines, pellet of $18 \times 10^{6}$ cells and membranes from $18 \times 10^{6}$ cells, obtained as reported above, were re-suspended in $150 \mu \mathrm{L}$ of PBS buffer (pH 7.4) and $10 \%{ }^{2} \mathrm{H}_{2} \mathrm{O}$, to obtain reference spectra, or of VLL-8 $(430 \mu \mathrm{M})$ in PBS buffer. STD spectra were acquired with 10,000 scans with on-resonance irradiation at $0.2 \mathrm{ppm}$ or $5.2 \mathrm{ppm}$ for saturation of membrane proteins or lipids resonances, respectively, 
and off-resonance irradiation at $30 \mathrm{ppm}$. A train of 40 Gaussian shaped pulses of $50 \mathrm{~ms}$ with $1 \mathrm{~ms}$ delay between pulses were used, for a total saturation time of $2 \mathrm{~s}$. STD spectra were obtained by internal subtraction of saturated spectrum from off-resonance spectrum by phase cycling. STD spectrum of the only peptide was also acquired and did not show any signal. 2D $\left[{ }^{1} \mathrm{H},{ }^{1} \mathrm{H}\right]$ TOCSY and NOESY spectra of VLL-28 in presence of isolated membranes were also acquired, similarly to those of the peptide alone.

All NMR data were processed with the software VNMRJ 1.1.D (Varian Inc.). 1D spectra were analyzed using ACD/NMR Processor 12.0 [www.acdlabs.com]. 2D TOCSY, COSY and NOESY spectra for proton chemical shift assignment were analyzed using Homoscope, a tool available in CARA (Computer Aided Resonance Assignment) software. Chemical shift assignments of VLL-28 in the absence of TFE are referred to residual water proton signals, (4.75 ppm), whereas in $25 \%$ TFE to residual TFE proton signals $(3.88 \mathrm{ppm})$. Chemical shift deviations from random coil values for $\mathrm{H \alpha}$ were calculated using the ChemShiftDeviationsFile script available in CARA.

\subsection{Zeta-potential measurements of bacterial and eukaryotic cells in the presence of $V L L-28$}

BL21 (DE3) E. coli cells were plated on Luria-Bertani agar overnight at $37{ }^{\circ} \mathrm{C}$. An isolated bacterial colony was used to inoculate Mueller Hinton Broth (MHB; OXOID, Hampshire, UK), and the bacterial culture was allowed to grow overnight at $37^{\circ} \mathrm{C} .100 \mu \mathrm{L}$ of culture was used to freshly inoculate $5 \mathrm{~mL}$ of MHB. The suspension was incubated at $37{ }^{\circ} \mathrm{C}$ for $\sim 2 \mathrm{~h}$, until a final bacterial concentration of $\sim 3 \times 10^{8}$ colony forming units per $\mathrm{mL}(\mathrm{CFU} / \mathrm{mL})$ was reached $\left(\mathrm{OD}_{600 \mathrm{~nm}} \sim 0.1\right)$. Bacterial suspensions were diluted using fresh MHB to $3 \times 10^{7} \mathrm{CFU} / \mathrm{mL}$ for zetapotential studies. Afterwards, cells were centrifuged at $12,000 \times g$ for $5 \mathrm{~min}$, and washed three times using $20 \mathrm{mM}$ sodium phosphates buffer, $\mathrm{pH}$ 7.4. The zeta-potential of bacterial cells was determined at $25^{\circ} \mathrm{C}$ from the mean of 3 measurements (50 runs each), in the absence and presence of different VLL-28 concentrations $(0-10 \mu \mathrm{M})$. Zeta-potential values were obtained by phase analysis light scattering (PALS) in a Zetasizer Nano ZS (Malvern Instruments, Malvern, UK), using disposable zeta cells with gold electrodes. Values of viscosity and refractive index were set to $0.8872 \mathrm{cP}$ and 1.330 , respectively.

Confluent BALBc 3T3 and SVT2 cells were washed with PBS buffer followed by trypsinization. Zeta potential measurements of eukaryotic cells were performed using the Diffusion Barrier Technique (Malvern, Application Note). $4 \times 10^{5}$ cells were dispensed into the disposable zeta cells with gold electrodes in PBS with and without the peptide (from 0 to $50 \mu \mathrm{M}$ ) and allowed to equilibrate for $30 \mathrm{~min}$ at $37{ }^{\circ} \mathrm{C}$. One measurement ( $\sim 70$ runs each) was performed with a constant voltage of $40 \mathrm{~V}$. The complete experiment was carried out at least two times using independent cellular suspensions.

\section{Results and discussion}

\subsection{Selective antitumor action of VLL-28 peptide}

To assess whether VLL-28 was endowed with anti-cancer activity, cytotoxicity assays were performed on malignant SVT2 mouse fibroblasts and parental non-malignant BALBc 3T3 mouse fibroblasts. Interestingly, these studies have shown that the peptide VLL-28 exerts a dose- and time-dependent inhibition of viability on malignant SVT2 murine fibroblasts (see Fig. 1a). Conversely, the peptide was found to be inactive towards the non-malignant line of BALBc 3T3 fibroblasts (Fig. 1b). This evidence was also confirmed by morphological analyses through light microscopy, where a severe alteration of cell morphology with the presence of cell debris was observed only in the case of SVT2 cancer cells, with an $\mathrm{IC}_{50}$ value of $10 \mu \mathrm{M}$ at $72 \mathrm{~h}$ (Fig. S1). Remarkably, this peptide was also found to be effective and selective against human tumor cell lines, as demonstrated by MTT assays performed on transformed HEK-293 cells (with an $\mathrm{IC}_{50}$ value of $10 \mu \mathrm{M}$ at $72 \mathrm{~h}$ ) and human primary renal cortical epithelial (HRCE) cells (Fig. S2). In agreement with these results, it has been previously reported that other AMPs, which are toxic for bacteria but not for normal mammalian cells, are instead cytotoxic for cancer cells [30].

\subsection{Internalization of VLL-28 peptide}

Most AMPs and ACPs share a common membranolytic mechanism of action that results first either in the selective disruption or permeation of the cancer cell membrane and then in the swelling of mitochondria. Nonetheless, a non-membranolytic mechanism of action is increasingly recognized as an alternative ACPs mechanism [31]. To test whether the selective antitumor activity of VLL-28 was associated to a membranolytic mechanism and/or to its internalization, we performed experiments by using the peptide labeled with fluorescein isothiocyanate (FITC). To this purpose, SVT2 and BALBc 3T3 cells were incubated for $12 \mathrm{~h}$ with $20 \mu \mathrm{M}$ FITC-labeled VLL-28, since this concentration of peptide turned out to be the most effective in terms of cytotoxicity. As shown in Fig. 2a, in the case of SVT2 cells, VLL-28 fluorescent signal appears to be mostly intracellular already after $12 \mathrm{~h}$ of incubation, thus indicating that the peptide is internalized into the target cancer cells. On the other hand, the peptide (green) mainly colocalizes with WGA (red) at the plasma membrane in BALBc 3T3 cells (as indicated by arrows in Fig. 2b). The lack of VLL-28 internalization into these latter cells is consistent with the absence of cytotoxicity emerged from viability tests (Fig. 1b). Fluorescent staining was found to be specific, as no fluorescent signals were observed in the absence of FITC-labeled peptide (data not shown). Since the internalization has been observed at a time point preceding the cell death (48-72 h), the molecular target of VLL-28 might be a not yet identified intracellular component.

\subsection{VLL-28 CD analyses in the presence of intact eukaryotic cells}

Since differences in the plasma membrane composition between normal and cancer cells are supposed to contribute to the selective permeability and toxicity of ACPs towards the latter, we resolved to examine if the presence of the two different cell lines affects differently the secondary structure of VLL-28. Interestingly, VLL-28 CD spectra registered in the presence of either BALBc 3T3 or SVT2 whole cells revealed a different behavior (Fig. 3). In particular, in the presence of BALBc 3T3 cells, VLL-28 seems to gradually get structured over time until a prevalence of helical structure is observed upon $1 \mathrm{~h}$ incubation (Fig. 3a). Indeed, the spectrum shows two minima, at 208 and $222 \mathrm{~nm}$, typical of helical structure, in agreement with $\mathrm{CD}$ data obtained in the presence of $n$-dodecyl-phosphatidylcholine (DPC), a well-known eukaryotic membrane mimetic agents [16]. Differently, in the presence of SVT2 intact cells, a drop in the CD signal is observed suggesting a fast internalization process of VLL-28, occurring already after $10 \mathrm{~min}$ (Fig. 3b), as confirmed by confocal microscopy data (Fig. 2).

\subsection{NMR conformational analysis of VLL-28}

In order to gain insight into the mechanism of action of VLL-28 and provide information on the basis of the different behaviors of VLL-28 with regard to the two studied cell lines, a NMR conformational analysis of the peptide in the absence and in the presence of TFE, a wellknown structuring solvent, has been initially carried out (Figs. S3 and S4). According with what previously observed by CD analysis [16], VLL-28 does not adopt a well-defined conformation in phosphate neutral solution, as indicated by sharp and low-dispersed resonances in both the amide/aromatic and the aliphatic regions (Fig. S3a). Upon addition of TFE $(25 \% \mathrm{v} / \mathrm{v})$, amide, aromatic and aliphatic proton resonances resulted significantly more dispersed (Fig. S3b). In particular, the tryptophan side chain $\mathrm{H}_{\mathrm{N}}$, clearly distinguishable at $10.14 \mathrm{ppm}$ in 
a

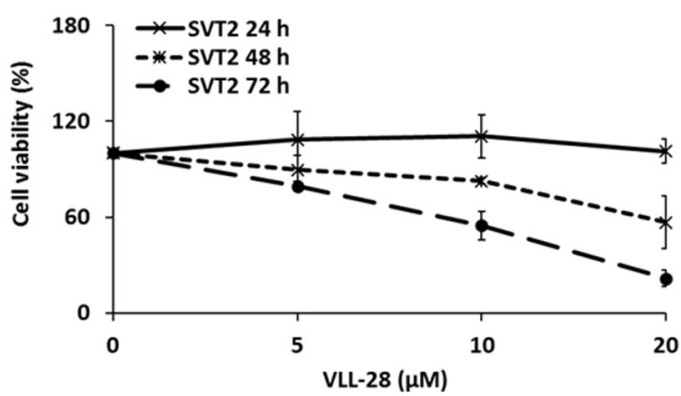

b

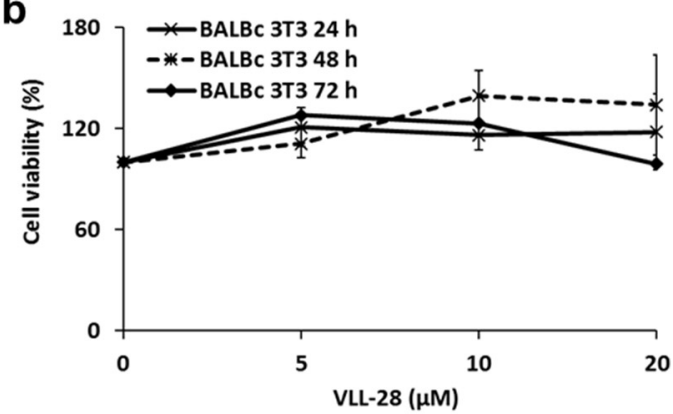

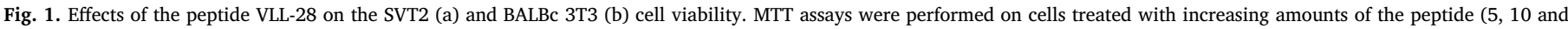

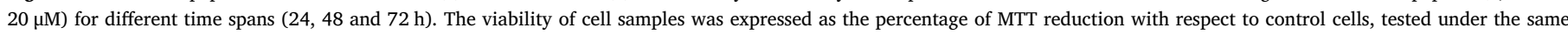

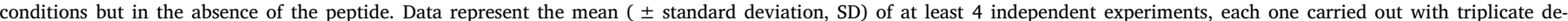
terminations. ${ }^{*} P<0.05,{ }^{* *} P<0.01$, or $* * * P<0.001$ were obtained for control versus treated samples in the case of SVT2 cells treated with VLL-28 peptide for 48 and $72 \mathrm{~h}$.

a

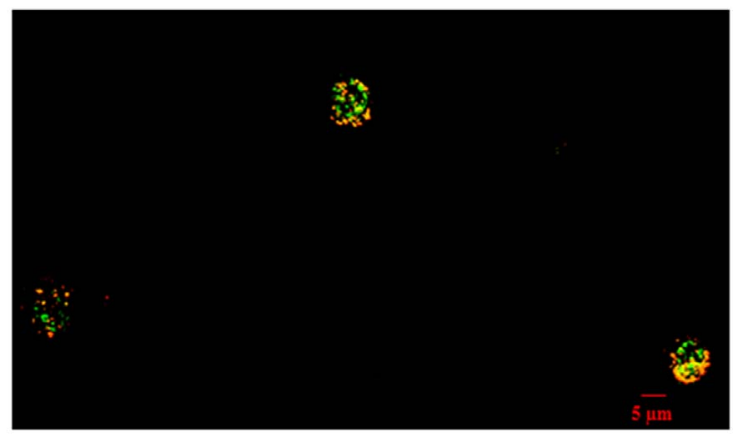

b

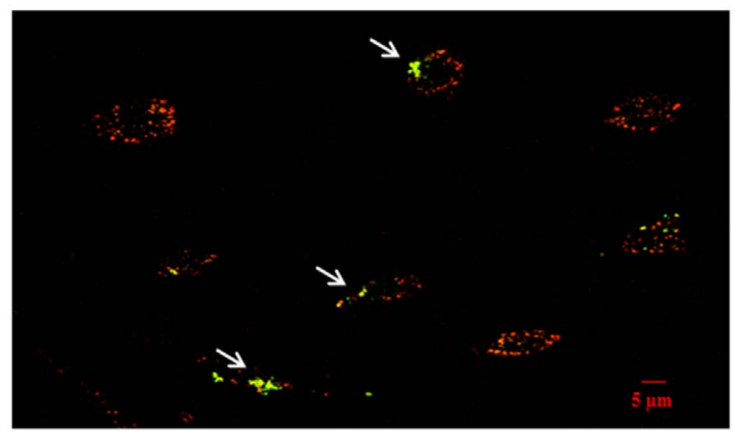

Fig. 2. Internalization of VLL-28 peptide in SVT2 (a) and BALBc 3T3 (b) cells. Cells were cultured on coverslips, incubated for $12 \mathrm{~h}$ with $20 \mu \mathrm{M}$ VLL-28 peptide (green) and stained with WGA ( $5 \mu \mathrm{g} / \mathrm{mL}$, Alexa Fluor ${ }^{\oplus 5} 54$ Conjugate). Cells were analyzed by confocal microscopy.

the absence of TFE (Fig. S3a, left), exhibits up-field shift at $9.94 \mathrm{ppm}$ upon addition of TFE (Fig. S3b, left), possibly induced by an aromaticaromatic long-range interaction. Moreover, $2 \mathrm{D}\left[{ }^{1} \mathrm{H},{ }^{1} \mathrm{H}\right]$ NOESY spectrum of VLL-28 peptide contains a consistent higher number of crosspeaks with respect of that recorded in the absence of TFE, indicating a more structured conformation (Fig. S4). Almost complete assignment of proton resonances of VLL-28 has been achieved in 25\% TFE by using a combination of TOCSY and NOESY spectra, according to the standard procedures (Table S1).

To assess the secondary structure of VLL-28 in 25\% TFE, analyses of the $\mathrm{H}_{\alpha}$ chemical shift deviations from random coil values $\left(\Delta \delta \mathrm{H}_{\alpha}\right)$ and of the NOE patterns were performed. Interestingly, two regions encompassing residues $\mathrm{V}^{37}-\mathrm{R}^{48}$ and $\mathrm{V}^{50}-\mathrm{S}^{59}$ showed large negative deviations $\left(\Delta \delta \mathrm{H}_{\alpha}<-0.1 \mathrm{ppm}\right)$, suggesting that the peptide mostly assumes a helical conformation, which is lost in the last C-terminal amino acids. (Fig. 4a). Accordingly, $\mathrm{H}_{\mathrm{N}}-\mathrm{H}_{\mathrm{N}}$ NOEs, together with $\mathrm{H}_{\alpha i^{-}} \mathrm{H}_{\mathrm{Ni}}+3$ and $\mathrm{H}_{\alpha i^{-}}$ $\mathrm{H}_{\beta i}+{ }_{3}$ NOEs, were observed starting from residues $\mathrm{V}^{37}$ to $\mathrm{S}^{59}$ only in the presence of TFE (Fig. $4 \mathrm{~b}$ and c), further confirming the helical structure of that region in TFE.

\subsection{STD NMR interaction studies of VLL-28 with tumor and normal cell membranes and definition of its binding epitopes}

To identify binding residues of VLL-28 saturation transfer difference (STD) NMR binding experiments of the peptide in the presence of intact SVT2 and BALBc 3T3 cells [32], as well as of their isolated membranes, were performed. Unfortunately, ${ }^{1} \mathrm{H}$ NMR VLL-28 proton resonances vanish in the presence of each of the two cell lines, thus hampering a detailed molecular analysis of the VLL-28 interaction with the cellular membranes (data not shown).

Very recently, we described the use of native cell membranes to overcome peptide cell internalization issues in "on-cell" NMR binding experiments [24]. This approach provides a significant improvement of NMR peptide spectra with respect to those acquired by using intact cells. Particularly, in the presence of isolated membranes, the ${ }^{1} \mathrm{H}$ NMR signals of the peptide are sharper and better resolved, the STD signals appear significantly stronger, and background signals of the cellular components result much weaker in both the ${ }^{1} \mathrm{H}$ and the STD spectra [24]. On the basis of the biochemical evidences of peptide internalization (see above), we carried out STD NMR experiments of the VLL-28 peptide in the presence of isolated membranes.

Interestingly, ${ }^{1} \mathrm{H}$ NMR peptide signals resulted well visible in the presence of both SVT2 and BALBc 3T3 cell membranes as in the sole buffer (Fig. S5), thus allowing to perform STD NMR binding studies. In particular, we evaluated the binding capability of VLL-28 to the two different components of the cell membrane, proteins and lipids, acquiring STD spectra at two different saturation frequencies, i.e. one to selectively saturate proteins $(0.2 \mathrm{ppm})$ and another one to saturate lipids (5.2 ppm) [33]. Remarkably, the ${ }^{1} \mathrm{H}$ STD spectra showed that VLL28 receives a detectable saturation transfer in the presence of cell membranes only when lipids are saturated (Fig. 5). This effect, which is negligible in the absence of cell membranes (Fig. 5b), provides a direct observation of the binding of VLL-28 to the lipid component of the cell membranes. This finding is in agreement with previous results showing that the peptide is able to interact with lipids mimicking bacterial membranes [16]. It is worth of note that differences in the STD spectra were observed for BALBc 3T3 and SVT2 cell membranes (Fig. 5). In particular, a higher number of STD signals, with stronger intensities, was observed in the presence of BALBc 3T3 cell membranes compared with those of SVT2 (Fig. 6a). In particular, all the binding residues of VLL-28 to the SVT2 cell membranes are in common with that of the BALBc 3T3 cell membranes. Specifically, VLL28 residues involved in both BALBc 3T3 and SVT2 interaction are $\mathrm{G}^{49}, \mathrm{Y}^{52}$ and $\mathrm{W}^{55}$ (Fig. 6b, highlighted in magenta). Moreover, one or both of the two threonine residues, $\mathrm{T}^{41}$ and $\mathrm{T}^{43}$, appear involved in the VLL-28 interaction with both cell lines. On the other hand, $\mathrm{Q}^{47}, \mathrm{~V}^{50}, \mathrm{I}^{51}$ and $\mathrm{F}^{58}$, together with the acetyl $\mathrm{N}$-terminal, show protons that are saturated only in the 
a

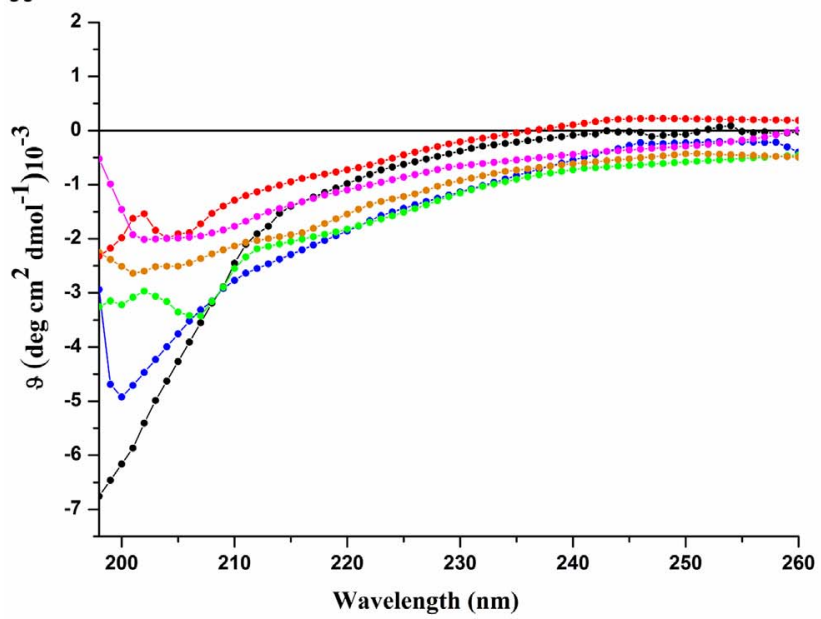

b

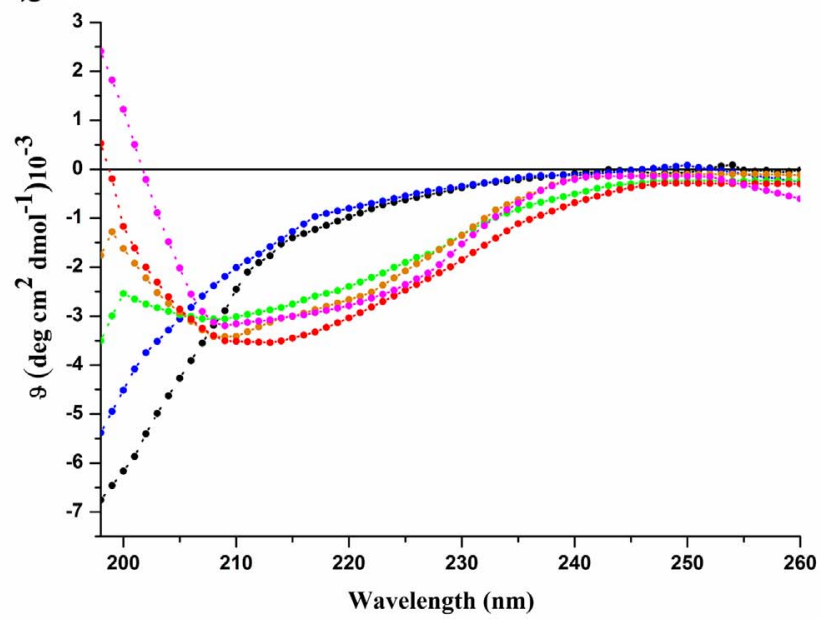

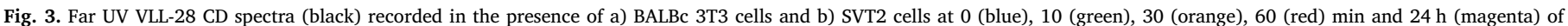
incubation.

presence of BALBc 3T3 membranes (Fig. 6b, highlighted in red). Furthermore, strong STD effects were observed for side-chains of arginine and lysine residues. However, due to the spectral overlap and to the presence of a high number of basic residues in the peptide sequence they could not identified unambiguously. Moreover, methyl of leucine $(\mathrm{L})$ and valine $(\mathrm{V})$ localized in the N-terminal region, seem to be involved as well.

Overall, these data indicate that the interaction of VLL-28 with cell membranes is mediated by the $\mathrm{N}$-terminal and the central regions $\left(\mathrm{V}^{37}\right.$. $\mathrm{F}^{58}$ ) (Fig. 6), which interestingly correspond to the portions of the peptide that assume helical conformation in presence of TFE. Specifically, the binding to both the cell membranes seems to be mainly mediated by aromatic and basic residues, as could be expected for peptide-lipid interactions.

Different STD intensities of the peptide induced by the interaction with BALBc 3T3 and SVT2 cell membranes are likely ascribed to a different interaction mechanism between the peptide and the two membranes. In particular, stronger STD effects observed in the presence of non-tumor BALBc 3T3 membranes indicates that a fast-exchange equilibrium between the free form and a well-recognized bound

a

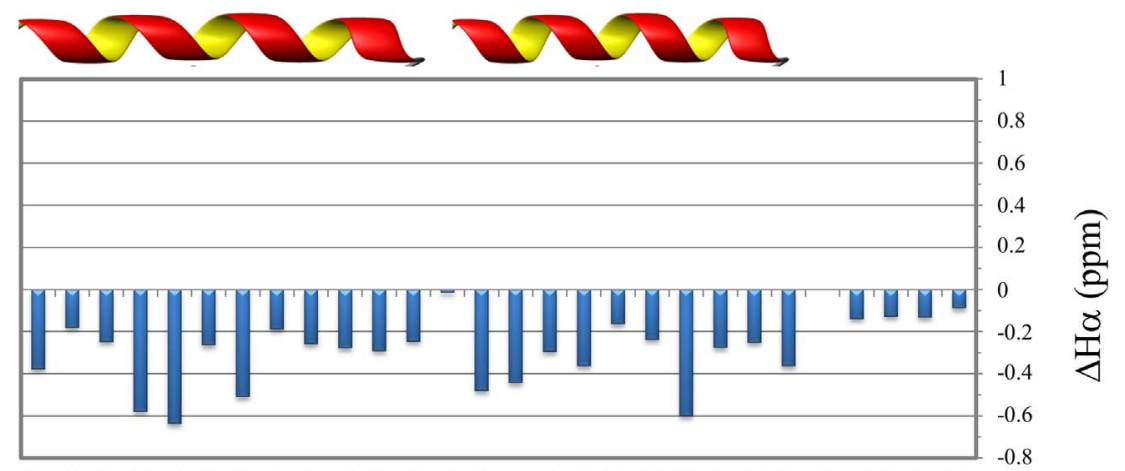

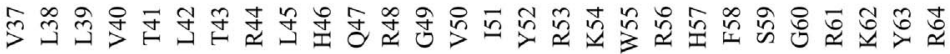

Residue Number
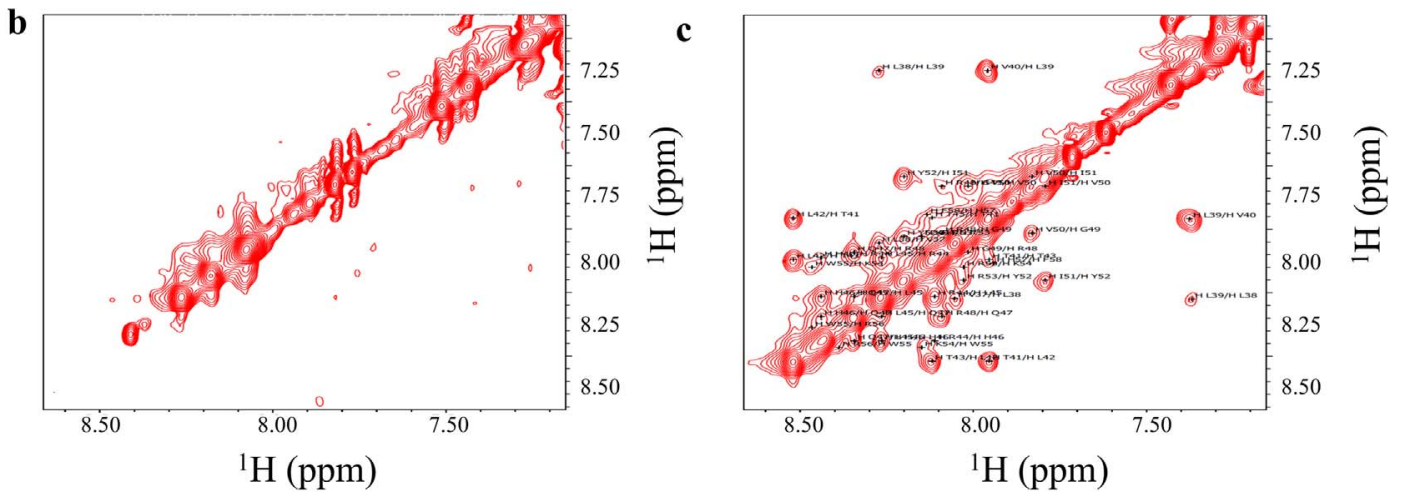

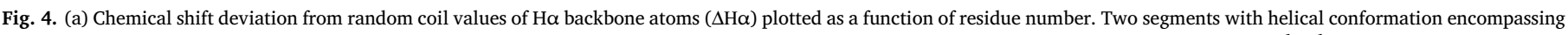

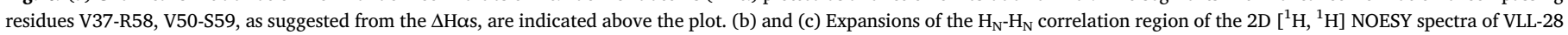

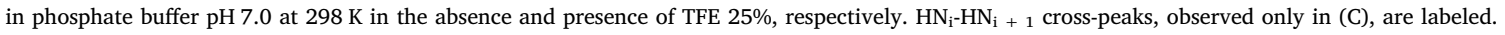




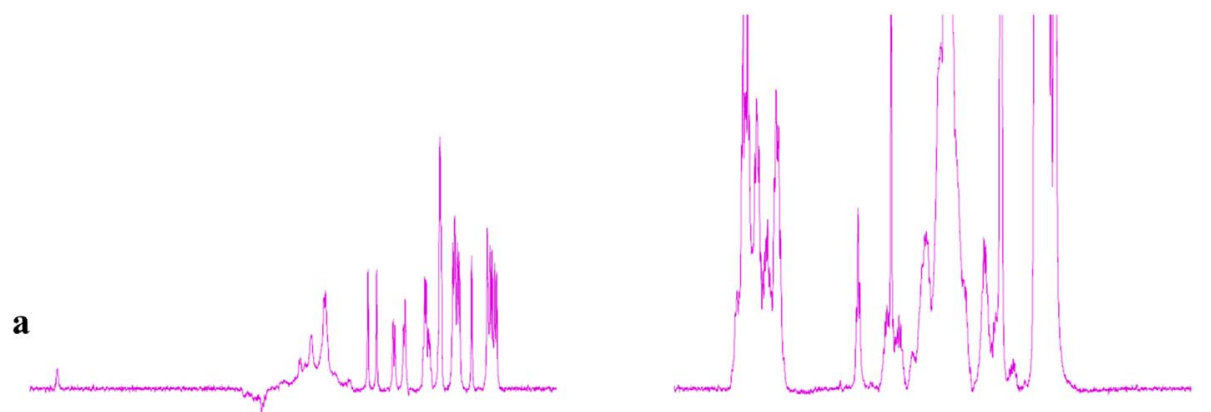

Fig. 5. Reference ${ }^{1} \mathrm{H}$ (a) and (STD)-NMR spectra of VLL-28 in the absence (b) and in the presence of SVT2 (C) and BALBc 3T3 (D) cell membranes.

b

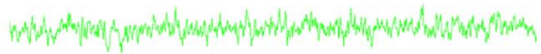

c

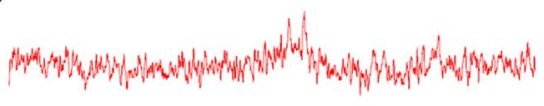

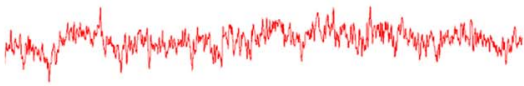
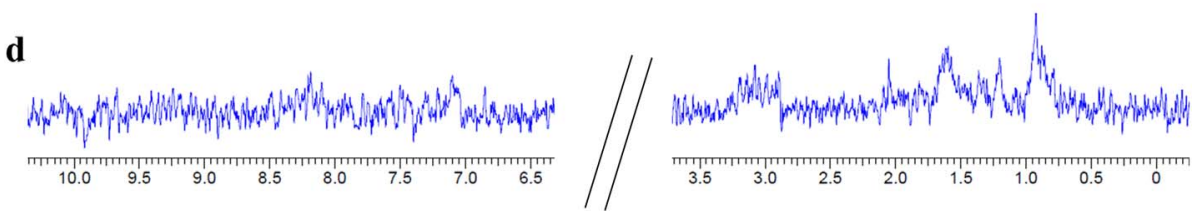

\section{${ }^{1} \mathrm{H}(\mathrm{ppm})$}

conformation occurs. Since fast-exchange regime is observed with lower affinity interaction, this could explain the inability of VLL-28 to penetrate these cell membranes. Differently, the reduced STD effects, observed in the presence of SVT2 membranes, can be ascribed to a stronger interaction with the cell membranes possibly being the first step of an internalization process.

\subsection{Effect of VLL-28 on zeta-potential of cell membranes}

Zeta potential of cell membranes has been used as a possible marker for the assessment of membrane damage and could be suitable to study the permeabilizing property of the VLL-28 peptide [34]. Zeta potential analyses were performed on E. coli, BALBc 3 T3 and SVT2 cells. The measured zeta potential in our experimental conditions for the cells in the absence of any peptide is $-43.93 \mathrm{mV}$ for $E$. coli (Fig. S6), $-6.91 \mathrm{mV}$ for BALBc 3T3 and $-11.2 \mathrm{mV}$ for SVT2 cells, respectively, indicating that their surfaces are all negatively charged and, as already known, that the surface of the bacterial membranes is more negatively charged than mammalian cells $[35,36]$. This is due to both lipid composition and negatively charged cell surface macromolecules, as described also for other systems [9]. Furthermore, Z-potential measurements clearly demonstrated that the surface of SVT2 has a more negative charge than BALBc 3T3 cells. The addition of VLL-28 caused an increase of Z-potential values towards neutralization indicating that the peptide is interacting with the surface of all the cells tested (Fig. 7a and $b$ and S6). Given the role of electrostatic interactions in driving the

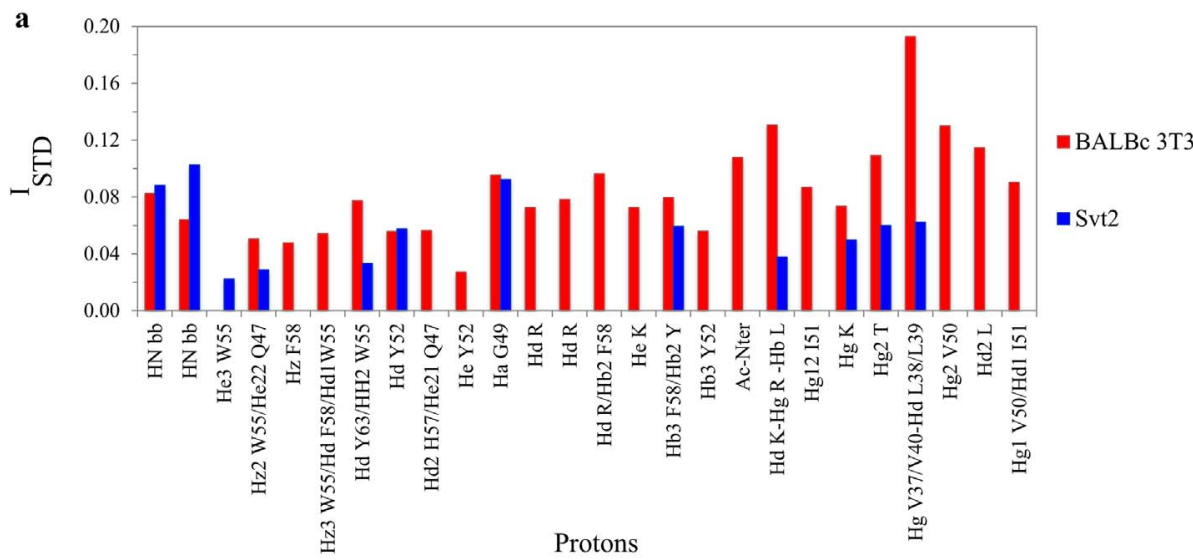

Fig. 6. (a) Bar graphs of STD signal intensities $\left(\mathrm{I}_{\mathrm{STD}}\right)$ for the VLL-28 $\mathrm{H}^{\mathrm{N}}$ /aromatic and aliphatic protons receiving saturation transfer in the presence of BALBc 3T3 (red bars) and SVT2 (blue bars) cell membranes. In the $\mathrm{x}$-axis label, $\mathrm{HNbb}=$ not assigned backbone amide protons, $\mathrm{R}=\mathrm{R}^{44} /$ $\mathrm{R}^{48} / \mathrm{R}^{53} / \mathrm{R}^{61} / \mathrm{R}^{64} ; \mathrm{K}=\mathrm{K}^{54} / \mathrm{K}^{64} ; \mathrm{Y}=\mathrm{Y}^{52} / \mathrm{Y}^{63} ; \mathrm{L}=\mathrm{L}^{38} / \mathrm{L}^{39} /$ $\mathrm{L}^{45} ; \mathrm{T}=\mathrm{T}^{41} / \mathrm{T}^{43}$. (b) The VLL-28 sequence is reported. VLL-28 residues showing STD effect in the presence of the both cell membranes are highlighted in magenta, whereas those affected only in the presence of BALBc 3T3 in red. Asterisks indicate that, due to overlapped proton resonances, one or both the threonine are possibly involved in the interaction with BALBc 3 T3 and SVT2 cell membranes. Residues that are not involved in the binding or that could not be identified unambiguously are indicated in black.

b
37
$*$
46
47
$56 \quad 57$
57 64
Ac-VLLVTLTRLH 
a

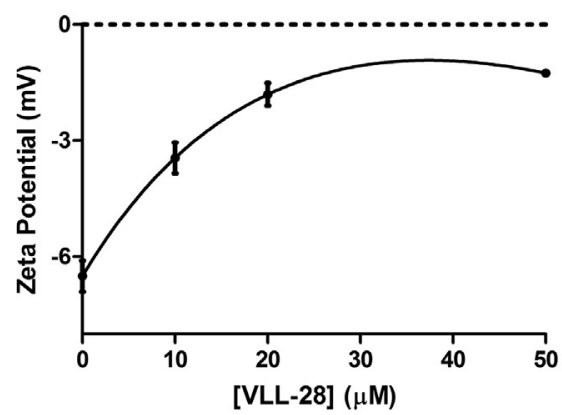

b

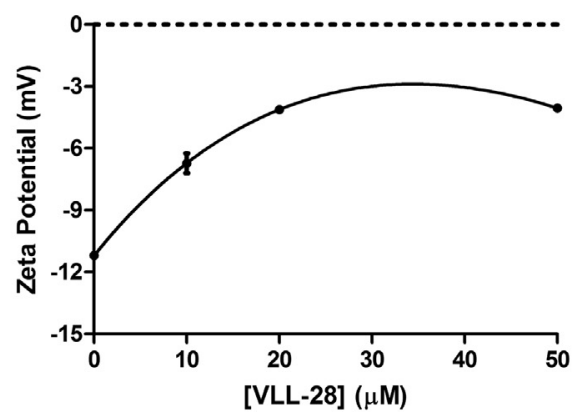

Fig. 7. a) VLL-28 effect on the Z-potential of BALBc 3T3 cells. b) VLL-28 effect on the Z-potential of SVT2 cells. At $4 \times 10^{5}$ cells $/ \mathrm{mL}$ cells were incubated and stabilized for 30 min with different peptide concentrations and the potential was measured at $37^{\circ} \mathrm{C}$. Data represent the mean ( \pm standard deviation, $S D$ ) of 2 independent experiments.

AMPs initial adsorption onto the extracellular surface, it is reasonable to question if VLL-28, as ACP, exerts the same kind of action. In accordance with the general mechanism of action of AMPs, VLL-28 fully neutralizes $E$. coli cell's surface potential to exert its antimicrobial action (Fig. S6). Differently, on eukaryotic cells, VLL-28 is able to increase the Z-potential but never reaching full neutralization even at concentrations $\geq 20 \mu \mathrm{M}$ thus indicating that total surface neutralization is not necessary to elicit its anticancer action [37].

\subsection{Cell death pathway activated by cell treatment with VLL-28}

To elucidate cell death pathways selectively activated by cell treatment with VLL-28, we performed western blot analyses by using antibodies specifically recognizing pro-caspase 3 and p62 proteins. The activation of procaspase- 3 to caspase- 3 is a key event in the apoptotic execution phase, since caspase- 3 is considered the most important among executioner caspases and is activated by any of the initiator caspases (caspase-8, caspase-9, or caspase-10) [38]. p62, instead, is generally used as a marker to study the autophagic flux, since it accumulates when autophagy is inhibited, whereas p62 decreased levels can be observed when autophagy is induced [39].

To get insight into cell death pathway induced by VLL-28, western blot analyses were performed on SVT2 cells in comparison with BALBc 3T3 (Fig. 8a-d). In SVT2 cells it was found a significant increase of p62 levels upon $6 \mathrm{~h}$ treatment with $20 \mu \mathrm{M}$ VLL-28 (Fig. 8a, d), indicative of

a

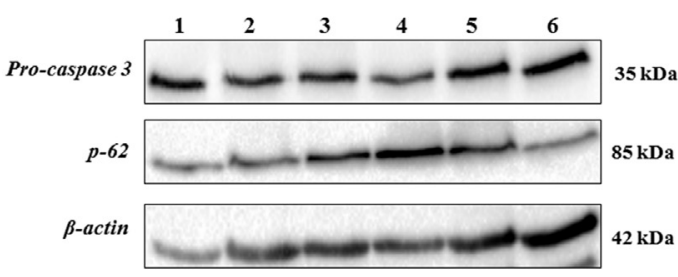

C

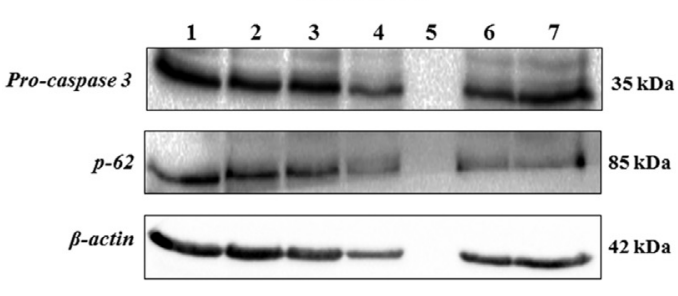

a stress leading to cell death with a consequent block of autophagy flux [40]. Accordingly, procaspase-3 levels appear lower than in control cells upon 6 and $12 \mathrm{~h}$ treatment (Fig. 8a, b), indicating a significant (about 30\%) activation of procaspase-3 to caspase-3 associated to apoptosis induction. This activation appears even stronger (about 50\%) after $24 \mathrm{~h}$ of treatment (Fig. 8a, b), and is associated to a significant decrease of p62 levels (Fig. 8a, d), in agreement with a time-dependent activation of apoptotic cell pathway.

In the case of non-malignant BALBc 3T3 cells, instead, no significant effects on procaspase- 3 levels were observed upon cell treatment with $20 \mu \mathrm{M}$ VLL-28 peptide at different time intervals $(6,12$ and $24 \mathrm{~h}$ ) (Fig. 8b, c), in agreement with the results reported above. This indicates that these cells are not susceptible to VLL-28 peptide toxic effects. Moreover, no significant effects were observed also when p62 levels were analyzed, except for $72 \mathrm{~h}$ treatment, where a slight increase of p62 levels was observed (Fig. 8b, d). Since no effects on cell viability were detected by MTT assays, this might be indicative of a slight cell perturbation counteracted by autophagy activation.

Hence, experimental data revealed that VLL-28 exerts its action through a time-dependent activation of apoptotic cell pathways as demonstrated by the maturation of procaspase-3 to the caspase-3 [41]. This is in agreement with data reported in the literature indicating that several potential ACPs are able to induce apoptosis in human cancer cell lines of different origin, such as breast, uterine cervix, liver and prostate [9]. Apoptosis induction, with some degree of selectivity

b

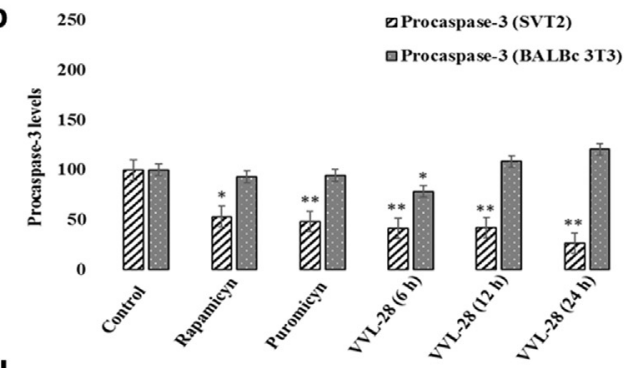

d

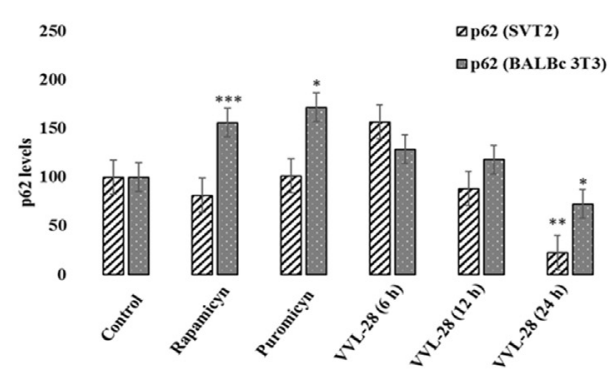

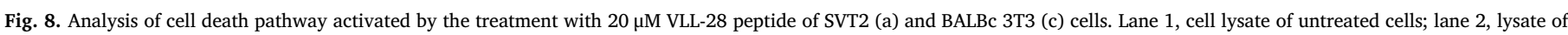

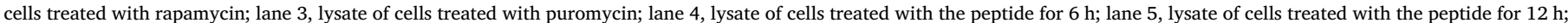

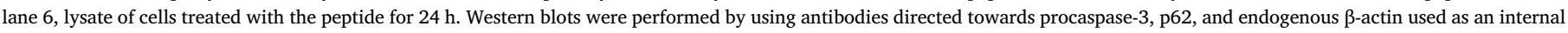

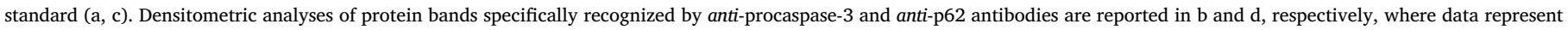
the mean ( \pm standard deviation, SD) of 3 independent experiments. ${ }^{*} P<0.05$, ${ }^{* *} P<0.01$, or ${ }^{* * *} P<0.001$ were obtained for control versus treated samples. 
towards cancer cells, has been described also in the case of ACPs effective on metastatic tumor cells or on cancer endothelial cells [9]. Since metastases are the main cause of conventional therapy failure, peptides able to specifically interfere with the process of metastases formation by stimulating apoptosis induction in neoplastic cells represent valuable resources in cancer treatment [9]. These observations associated to the strong and selective toxic effects exerted by VLL-28 peptide towards cancer cells open interesting perspective to future applications of this peptide.

\section{Concluding remarks}

The cytotoxic activities of several AMPs turn this group of molecules into an amazing pool of new templates for anticancer drug development [42]. Accordingly, VLL-28, previously identified as an AMP [16], is here found to be endowed also with selective cytotoxic activity towards both murine and human cancer cells, thus pointing to VLL-28 as a potential chemotherapeutic agent. Microorganisms belonging to the archaeal kingdom have been so far considered as source of biotechnologically relevant enzymes and proteins [43-51], but there are no reports regarding potential ACPs isolated from this kingdom. This paper represents the first evidence that archaeal microorganisms could bear also an unexplored repertoire of such kind of molecules exerting a transkingdom action. Given the intrinsic stability to physical and chemical agents of Stf76, the parental source of VLL-28, it is foreseen that VLL-28 might be a promising "lead compound" for future development of novel drugs, upon chemical modifications, i.e. D-amino acids, an all-hydrocarbon bridge, and/or modified amide bounds to further increase its stability to proteases [22].

\section{Transparency document}

The http://dx.doi.org/10.1016/j.bbagen.2017.06.009 associated with this article can be found, in online version.

\section{Appendix A. Supplementary data}

Supplementary data to this article can be found online at http://dx. doi.org/10.1016/j.bbagen.2017.06.009.

\section{References}

[1] S.C. Mansour, O.M. Pena, R.E. Hancock, Host defense peptides: front-line immunomodulators, Trends Immunol. 35 (2014) 443-450.

[2] J. Wiesner, A. Vilcinskas, Antimicrobial peptides: the ancient arm of the human immune system, Virulence 1 (2010) 440-464.

[3] A.L. Hilchie, K. Wuerth, R.E.W. Hancock, Immune modulation by multifaceted cationic host defense (antimicrobial) peptides, Nat. Chem. Biol. 9 (2013) 761-768.

[4] K.C.L. Mulder, L.A. Lima, V.J. Miranda, S.C. Dias, O.L. Franco, Current scenario of peptide-based drugs: the key roles of cationic antitumor and antiviral peptides, Front. Microbiol. 4 (2013).

[5] M. Pushpanathan, P. Gunasekaran, J. Rajendhran, Antimicrobial peptides: versatile biological properties, Int. J. Pept. 2013 (2013) 675391.

[6] S. Riedl, D. Zweytick, K. Lohner, Membrane-active host defense peptides - challenges and perspectives for the development of novel anticancer drugs, Chem. Phys. Lipids 164 (2011) 766-781.

[7] R.E.W. Hancock, E.F. Haney, E.E. Gill, The immunology of host defence peptides: beyond antimicrobial activity, Nat. Rev. Immunol. 16 (2016) 321-334.

[8] V. Teixeira, M.J. Feio, M. Bastos, Role of lipids in the interaction of antimicrobial peptides with membranes, Prog. Lipid Res. 51 (2012) 149-177.

[9] D. Gaspar, A.S. Veiga, M.R.B. Castanho, From antimicrobial to anticancer peptides. A review, Front. Microbiol. 4 (2013).

[10] G. Gabernet, A.T. Muller, J.A. Hiss, G. Schneider, Membranolytic anticancer peptides, Med. Chem. Commun. 7 (2016) 2232-2245.

[11] A.L. Rerole, J. Gobbo, A. De Thonel, E. Schmitt, J.P. Pais de Barros, A. Hammann, D. Lanneau, E. Fourmaux, O.N. Demidov, O. Micheau, L. Lagrost, P. Colas, G. Kroemer, C. Garrido, Peptides and aptamers targeting HSP70: a novel approach for anticancer chemotherapy, Cancer Res. 71 (2011) 484-495.

[12] I. Kuriyama, A. Miyazaki, Y. Tsuda, H. Yoshida, Y. Mizushina, Inhibitory effect of novel somatostatin peptide analogues on human cancer cell growth based on the selective inhibition of DNA polymerase beta, Bioorg. Med. Chem. 21 (2013) 403-411.

[13] K. Pane, L. Durante, O. Crescenzi, V. Cafaro, E. Pizzo, M. Varcamonti,
A. Zanfardino, V. Izzo, A. Di Donato, E. Notomista, Antimicrobial potency of cationic antimicrobial peptides can be predicted from their amino acid composition: application to the detection of "cryptic" antimicrobial peptides, J. Theor. Biol. 419 (2017) 254-265.

[14] R. Gaglione, E. Dell'Olmo, A. Bosso, M. Chino, K. Pane, F. Ascione, F. Itri, S. Caserta, A. Amoresano, A. Lombardi, H.P. Haagsman, R. Piccoli, E. Pizzo, E.J. Veldhuizen, E. Notomista, A. Arciello, Novel human bioactive peptides identified in apolipoprotein B: evaluation of their therapeutic potential, Biochem. Pharmacol. (2017).

[15] K. Pane, V. Sgambati, A. Zanfardino, G. Smaldone, V. Cafaro, T. Angrisano, E. Pedone, S. Di Gaetano, D. Capasso, E.F. Haney, V. Izzo, M. Varcamonti, E. Notomista, R.E.W. Hancock, A. Di Donato, E. Pizzo, A new cryptic cationic antimicrobial peptide from human apolipoprotein $\mathrm{E}$ with antibacterial activity and immunomodulatory effects on human cells, FEBS J. 283 (2016) 2115-2131.

[16] E. Notomista, A. Falanga, S. Fusco, L. Pirone, A. Zanfardino, S. Galdiero, M. Varcamonti, E. Pedone, P. Contursi, The identification of a novel Sulfolobus islandicus CAMP-like peptide points to archaeal microorganisms as cell factories for the production of antimicrobial molecules, Microb. Cell Factories 14 (2015).

[17] P. Contursi, B. Farina, L. Pirone, S. Fusco, L. Russo, S. Bartolucci, R. Fattorusso, E. Pedone, Structural and functional studies of Stf76 from the Sulfolobus islandicus plasmid-virus pSSVx: a novel peculiar member of the winged helix-turn-helix transcription factor family, Nucleic Acids Res. 42 (2014) 5993-6011.

[18] E. Galano, A. Arciello, R. Piccoli, D.M. Monti, A. Amoresano, A proteomic approach to investigate the effects of cadmium and lead on human primary renal cells, Metallomics 6 (2014) 587-597.

[19] D.M. Monti, D. Guarnieri, G. Napolitano, R. Piccoli, P. Netti, S. Fusco, A. Arciello, Biocompatibility, uptake and endocytosis pathways of polystyrene nanoparticles in primary human renal epithelial cells, J. Biotechnol. 193 (2015) 3-10.

[20] A. Arciello, N. De Marco, R. Del Giudice, F. Guglielmi, P. Pucci, A. Relini, D.M. Monti, R. Piccoli, Insights into the fate of the N-terminal amyloidogenic polypeptide of ApoA-I in cultured target cells, J. Cell. Mol. Med. 15 (2011) 2652-2663.

[21] G. Smaldone, D. Diana, L. Pollegioni, S. Di Gaetano, R. Fattorusso, E. Pedone, Insight into conformational modification of alpha-synuclein in the presence of neuronal whole cells and of their isolated membranes, FEBS Lett. 589 (2015) $798-804$.

[22] I. de Paola, L. Pirone, M. Palmieri, N. Balasco, L. Esposito, L. Russo, D. Mazza, L. Di Marcotullio, S. Di Gaetano, G. Malgieri, L. Vitagliano, E. Pedone, L. Zaccaro, Cullin3-BTB interface: a novel target for stapled peptides, PLoS One 10 (2015).

[23] S. Correale, C. Esposito, L. Pirone, L. Vitagliano, S.D. Gaetano, E. Pedone, A biophysical characterization of the folded domains of KCTD12: insights into interaction with the GABAB2 receptor, J. Mol. Recognit. 26 (2013) 488-495.

[24] B. Farina, I. de Paola, L. Russo, D. Capasso, A. Liguoro, A. Del Gatto, M. Saviano, P.V. Pedone, S. Di Gaetano, G. Malgieri, L. Zaccaro, R. Fattorusso, A combined NMR and computational approach to determine the RGDechi-hCit-alpha(v)beta(3) integrin recognition mode in isolated cell membranes, Chem. Eur. J. 22 (2016) 681-693.

[25] A. Bax, D.G. Davis, Mlev-17-based two-dimensional homonuclear magnetization transfer spectroscopy, J. Magn. Reson. 65 (1985) 355-360.

[26] M. Rance, O.W. Sorensen, G. Bodenhausen, G. Wagner, R.R. Ernst, K. Wuthrich, Improved spectral resolution in cosy $1 \mathrm{H}$ NMR spectra of proteins via double quantum filtering, Biochem. Biophys. Res. Commun. 117 (1983) 479-485.

[27] A. Kumar, R.R. Ernst, K. Wuthrich, A two-dimensional nuclear Overhauser enhancement (2D NOE) experiment for the elucidation of complete proton-proton cross-relaxation networks in biological macromolecules, Biochem. Biophys. Res. Commun. 95 (1980) 1-6.

[28] T.L. Hwang, A.J. Shaka, Water suppression that works - excitation sculpting using arbitrary wave-forms and pulsed-field gradients, J. Magn. Reson. Ser. A 112 (1995) 275-279.

[29] C. Dalvit, Efficient multiple-solvent suppression for the study of the interactions of organic solvents with biomolecules, J. Biomol. NMR 11 (1998) 437-444.

[30] D.W. Hoskin, A. Ramamoorthy, Studies on anticancer activities of antimicrobial peptides, BBA-Biomembranes 1778 (2008) 357-375.

[31] F. Schweizer, Cationic amphiphilic peptides with cancer-selective toxicity, Eur. J. Pharmacol. 625 (2009) 190-194.

[32] G. Malgieri, C. Avitabile, M. Palmieri, L.D. D'Andrea, C. Isernia, A. Romanelli, R. Fattorusso, Structural basis of a temporin $1 \mathrm{~b}$ analogue antimicrobial activity against gram negative bacteria determined by CD and NMR techniques in cellular environment, ACS Chem. Biol. 10 (2015) 965-969.

[33] X. Pan, M. Wilson, C. McConville, M.-A. Brundler, T.N. Arvanitis, J.P. Shockcor, J.L. Griffin, R.A. Kauppinen, A.C. Peet, The lipid composition of isolated cytoplasmic lipid droplets from a human cancer cell line, BE(2)M17, Mol. BioSyst. 8 (2012) 1694-1700.

[34] S. Halder, K.K. Yadav, R. Sarkar, S. Mukherjee, P. Saha, S. Haldar, S. Karmakar, T. Sen, Alteration of zeta potential and membrane permeability in bacteria: a study with cationic agents, Spring 4 (2015).

[35] R.E.W. Hancock, H.G. Sahl, Antimicrobial and host-defense peptides as new antiinfective therapeutic strategies, Nat. Biotechnol. 24 (2006) 1551-1557.

[36] D. Gaspar, J.M. Freire, T.R. Pacheco, J.T. Barata, M.A.R.B. Castanho, Apoptotic human neutrophil peptide- 1 anti-tumor activity revealed by cellular biomechanics, BBA-Mol. Cell. Res. 1853 (2015) 308-316.

[37] D. Gaspar, A.S. Veiga, C. Sinthuvanich, J.P. Schneider, M.A.R.B. Castanho, Anticancer peptide SVS-1: efficacy precedes membrane neutralization, Biochemistry 51 (2012) 6263-6265.

[38] S. Elmore, Apoptosis: a review of programmed cell death, Toxicol. Pathol. 35 (2007) 495-516.

[39] G. Bjorkoy, T. Lamark, S. Pankiv, A. Overvatn, A. Brech, T. Johansen, Monitoring 
autophagic degradation of P62/Sqstm1, Methods Enzymol. 452 (Pt B, 452) (2009) 181-197.

[40] A. Gonzalez-Rodriguez, R. Mayoral, N. Agra, M.P. Valdecantos, V. Pardo, M.E. Miquilena-Colina, J. Vargas-Castrillon, O. Lo Iacono, M. Corazzari, G.M. Fimia, M. Piacentini, J. Muntane, L. Bosca, C. Garcia-Monzon, P. Martin-Sanz, A.M. Valverde, Impaired autophagic flux is associated with increased endoplasmic reticulum stress during the development of NAFLD, Cell Death Dis. 5 (2014).

[41] Y. Huang, Q. Feng, Q. Yan, X. Hao, Y. Chen, Alpha-helical cationic anticancer peptides: a promising candidate for novel anticancer drugs, Mini Rev. Med. Chem. 15 (2015) 73-81.

[42] C.M.A.R.B, D. Gaspar, Host Defense Peptides and Their Potential as Therapeutic Agents, (2016).

[43] S. Prato, R.M. Vitale, P. Contursi, G. Lipps, M. Saviano, M. Rossi, S. Bartolucci, Molecular modeling and functional characterization of the monomeric primasepolymerase domain from the Sulfolobus solfataricus plasmid pIT3, FEBS J. 275 (2008) 4389-4402.

[44] S. Fusco, Q. She, S. Bartolucci, P. Contursi, T(lys), a newly identified Sulfolobus spindle-shaped virus 1 transcript expressed in the lysogenic state, encodes a DNAbinding protein interacting at the promoters of the early genes, J. Virol. 87 (2013)
5926-5936.

[45] S. Fusco, Q.X. She, G. Fiorentino, S. Bartolucci, P. Contursi, Unravelling the role of the F55 regulator in the transition from lysogeny to UV induction of Sulfolobus spindle-shaped virus 1, J. Virol. 89 (2015) 6453-6461.

[46] S. Fusco, M. Aulitto, S. Bartolucci, P. Contursi, A standardized protocol for the UV induction of Sulfolobus spindle-shaped virus 1, Extremophiles 19 (2015) 539-546.

[47] P. Contursi, S. Fusco, R. Cannio, Q.X. She, Molecular biology of fuselloviruses and their satellites, Extremophiles 18 (2014) 473-489.

[48] P. Contursi, S. Fusco, D. Limauro, G. Fiorentino, Host and viral transcriptional regulators in Sulfolobus: an overview, Extremophiles 17 (2013) 881-895.

[49] S. Bartolucci, P. Contursi, G. Fiorentino, D. Limauro, E. Pedone, Responding to toxic compounds: a genomic and functional overview of Archaea, Front. Biosci. (Landmark Ed) 18 (2013) 165-189.

[50] P. Contursi, R. Cannio, Q.X. She, Transcription termination in the plasmid/virus hybrid pSSVx from Sulfolobus islandicus, Extremophiles 14 (2010) 453-463.

[51] S. Prato, R. Cannio, H.P. Klenk, P. Contursi, M. Rossi, S. Bartolucci, pIT3, a cryptic plasmid isolated from the hyperthermophilic crenarchaeon Sulfolobus solfataricus IT3, Plasmid 56 (2006) 35-45. 